\title{
Retinoblastoma Susceptibility Gene Product Retrieval in Formalin-fixed, Paraffin-embedded Tissue : A Heating Method for Enhancing Immunohistochemical Staining
}

\author{
Yoshiro Tsuji $^{1,2}$, Katsuyuki Kusuzaki', Yasusuke Hirasawa ${ }^{1}$, Massimo Serra ${ }^{3}$, \\ Nicola Baldini ${ }^{3}$ and Mario Campanacci ${ }^{3}$ \\ 'Department of Orthopaedic Surgery, Kyoto Prefectural University of Medicine, Kyoto 602-0841, 2 Department of \\ Orthopaedic Surgery, Yokaichi National Hospital, Shiga 527-8505 and ${ }^{3}$ Department of Research Oncology, \\ Rizzoli Orthopaedic Institute, Bologna, Italy
}

Received for publication October 20, 1997 and in revised form February 19, 1998

\begin{abstract}
We examined immunohistochemical methods to visualize the retinoblastoma susceptibility gene product (RB) in formalin-fixed, paraffinembedded sections of the U2-OS and Saos-2 human osteosarcoma cell lines. Immunocytochemical studies showed clear staining with an anti-RB antibody in $88 \%$ of the smeared U2-OS cells and in none of the smeared Saos-2 cells. Antigen retrieval methods evaluated included microwaveoven and autoclave pretreatment of paraffinembedded sections immersed in Dulbecco's
\end{abstract}

phosphate buffered saline (pH 7.4) prior to incubation with the primary antibody. Strong and discrete staining of U2-OS cell nuclei for RB was seen after autoclave treatment, stronger than that seen following microwave-oven heating. Moreover, neither microwave-oven nor autoclave pretreatment produced positive staining in the nuclei of Saos- 2 cells. Therefore, tissues previously considered unsuitable for immunohistochemical analysis of the RB can be studied after autoclave treatment.

Key words: Immunohistochemistry, Retinoblastoma susceptibility gene product, Antigen retrieval, Autoclave treatment

\section{Introduction}

Advances in immunohistochemistry have led to the development of highly specific stains with important research and diagnostic applications. Some antigens, however, are difficult to detect by established methods because fixation and paraffin embedding procedures may destroy immunoreactivity. Shi et al. have shown that microwave-oven heating of tissue sections in the presence of metal solutions effectively retrieves many antigens [7]. Shin $e$ t al. have reported that autoclave pretreatment can uncover masked antigens [8]. In this study, we compared the retrieval of the retinoblastoma susceptibility gene product $(\mathrm{RB})$ in the formalin-fixed, paraffin-embedded in human osteosarcoma cell lines using microwave-oven heating and autoclave treatment

Correspondence to: Yoshiro Tsuji, M.D., Department of Orthopaedic Surgery, Yokaichi National Hospital, 255 Gochicho, Yokaichi, Shiga 527-8505, Japan.

\section{Materials and Methods}

\section{Cell preparation}

The U2-OS and Saos-2 cell lines were purchased from the American Type Culture Collection (Rockville, MD, USA). The U2-OS cell line, which produces the retinoblastoma gene product, was used as a positive control [6]. The Saos- 2 cell line was used as a negative control because this cell line does not express RB $[4,6]$. Each cell line was seeded in plastic dishes (Corning, Park Acton, MA, USA) containing DMEM (Gibco, Paisley, Scotland) supplemented with $10 \%$ fetal calf serum (Biological Industries, Kibbutz Beth Haemek, Israel) and incubated at $37^{\circ} \mathrm{C}$ in a humidified atmosphere containing $5 \% \mathrm{CO}_{2}$. The medium was replaced 3 days after seeding. The cells were harvested 6 days after seeding for use during the experiments.

\section{Immunocytochemical staining}

Cells were first rinsed with Dulbecco's phosphate buffered saline (PBS, pH 7.4) (Gibco, Paisley, Scotland) and then harvested with $1 \%$ trypsin (Gibco, Paisley, Scotland) in PBS at $37^{\circ} \mathrm{C}$ for $3 \mathrm{~min}$. The isolated cells were smeared onto glass slides by cytospin at $1000 \mathrm{rpm}$ for $10 \mathrm{~min}$ and 
fixed with $4 \%$ buffered paraformaldehyde (PFA) (Sigma Chemical Co., St. Louis, MO, USA) in PBS at room temperature for $10 \mathrm{~min}$. After removing the fixing solution, endogenous peroxidase activity was blocked with $1 \% \mathrm{H}_{2} \mathrm{O}_{2}$ (Sigma Chemical Co., St. Louis, MO, USA) in methanol (Carlo Erba, Milano, Italy) for $30 \mathrm{~min}$. Slides were washed with PBS and incubated overnight at $4^{\circ} \mathrm{C}$ with anti-RB protein antibody (1F8, Santa Cruz Biotechnology, CA, USA) at a concentration of $2 \mu \mathrm{g} / \mathrm{ml}$. Sites of antibody-antigen binding were visualized by sequential treatment with biotinylated anti-mouse IgG antibody (Dakopatts, Glostrup, Denmark) at $1: 300$ for $30 \mathrm{~min}$, streptavidin-biotinylated peroxidase complex (Dakopatts, Glostrup, Denmark) at 1:50 for $30 \mathrm{~min}$, and finally, 3,3'-diaminobenzidine tetrahydrochloride (Sigma Chemical Co., St. Louis, MO, USA) solution in the presence of $\mathrm{H}_{2} \mathrm{O}_{2}$. Hematoxylin counterstaining was not performed.

\section{Immunohistochemical staining}

Harvested cells were rinsed twice with PBS and centrifuged at $1000 \mathrm{rpm}$ for $5 \mathrm{~min}$. The resulting cell pellets were fixed with $10 \%$ buffered formalin (Sigma Chemical Co., St. Louis, MO, USA) in PBS at room temperature for $24 \mathrm{hr}$. And then, the fixing solution was replaced with $0.02 \mathrm{M}$ PBS containing $5 \%$ sucrose $(\mathrm{pH} 7.4)$ and the cell pellets were incubated overnight at $4^{\circ} \mathrm{C}$ with $0.02 \mathrm{M}$ PBS containing $5 \%$ sucrose $(\mathrm{pH} 7.4)$. The cell pellets were dehydrated at $4^{\circ} \mathrm{C}$ by $80 \%$ ethanol, $96 \%$ ethanol, $100 \%$ ethanol and acetone each for $1 \mathrm{hr}$. The cell pellets were incubated in xylene at $4^{\circ} \mathrm{C}$ for $5 \mathrm{~min}$, and the solution was changed by centrifugation at $1000 \mathrm{rpm}$ for $5 \mathrm{~min}$. The cell pellets were embedded in paraffin (Sherwood Medical, Athy, Ireland) at a maximum of $50^{\circ} \mathrm{C}$. Sections were cut $4 \mu \mathrm{m}$ thick and placed on glass slides coated with poly-l lysine (Sigma Chemical Co., St. Louis, MO, USA).

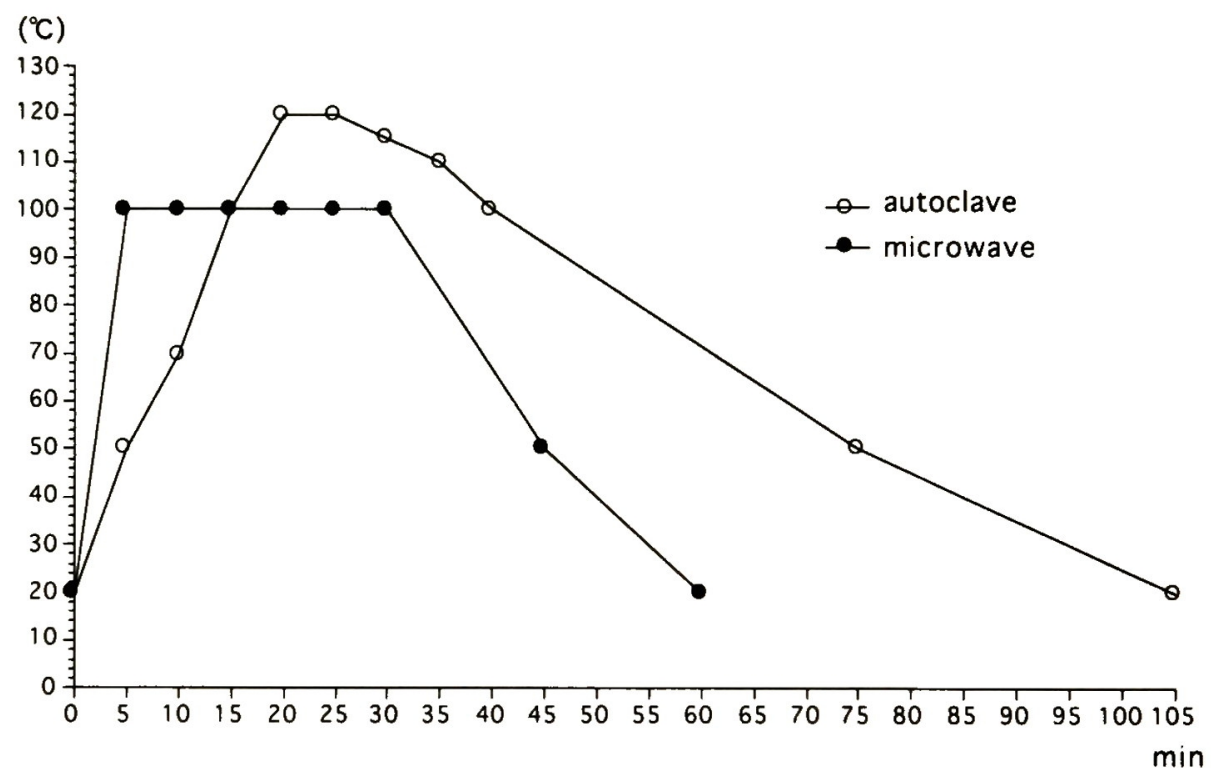

Fig. 1. Autoclave and microwave heating pretreatment. Open circles show autoclave treatment and closed circles indicate microwave heating.
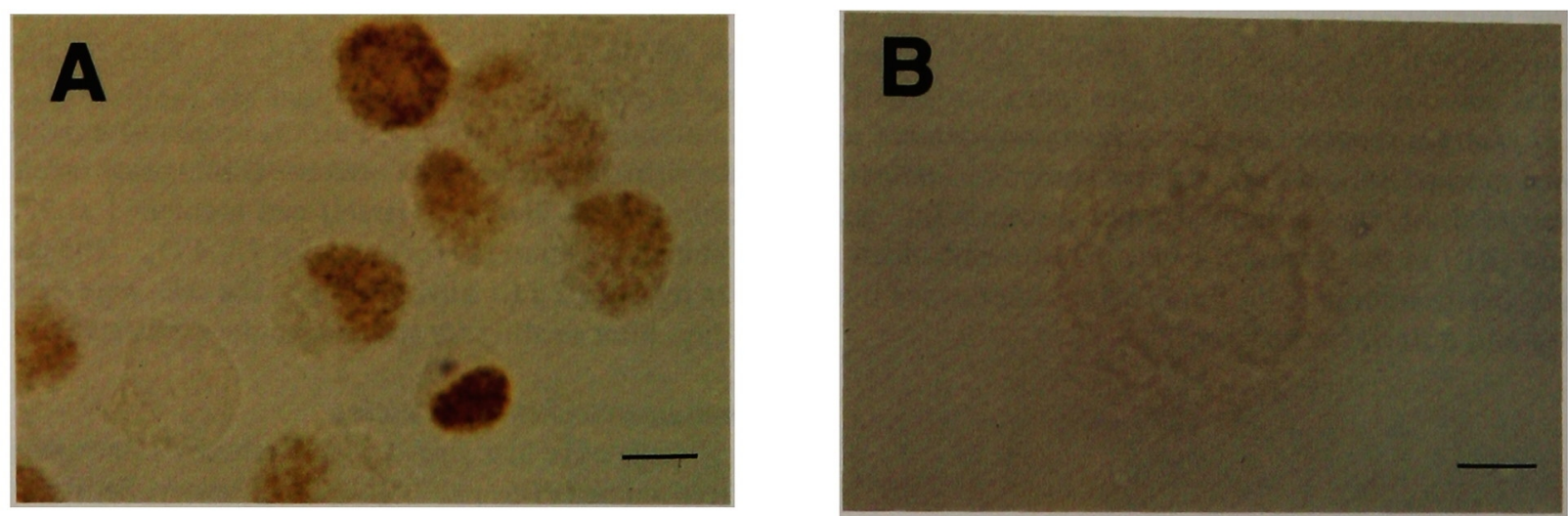

Fig. 2. Immunocytochemical staining of the RB in the U2-OS and Saos-2 human osteosarcoma cell lines. Smeared cells were fixed with $4 \%$ PFA, and were not embedded in paraffin. A: U2-OS cells with a clear nuclear signal $(\times 100)$. B: Saos-2 cells lack staining for the RB $(\times 100)$. $\mathrm{Bar}=20 \mu \mathrm{m}$. 
Sections were deparaffinized in xylene and then rehydrated with water. Endogenous peroxidase activity was blocked with $1 \% \mathrm{H}_{2} \mathrm{O}_{2}$ in methanol for $30 \mathrm{~min}$. The slides were washed with distilled water for $5 \mathrm{~min}$, placed in glass Coplin jars containing PBS, and divided into three groups. Sections were either stained with a conventional avidinbiotin complex (ABC) method (group 1), pretreated by microwave-oven (Bio-Rad Laboratories, Hercules, CA, USA) heating at $100^{\circ} \mathrm{C}$ for $25 \mathrm{~min}$ (group 2), or pretreated by autoclave (PBI International, Milano, Italy) heating at $120^{\circ} \mathrm{C}$ for $5 \mathrm{~min}$ (group 3) prior to incubation with the anti-RB antibody. After heating, the Coplin jars were allowed to cool in the microwave-oven or the autoclave and removed when the temperature reached $50^{\circ} \mathrm{C}$. The Coplin jars were then allowed to cool for $30 \mathrm{~min}$ at room temperature (Fig. 1). Slides were incubated with the anti-RB antibody at a concentration of $2 \mu \mathrm{g} / \mathrm{ml}$ overnight at $4^{\circ} \mathrm{C}$. The remaining steps were as described for the immunocytochemical staining.

\section{Results}

Immunocytochemical studies revealed that $88 \%$ of the nuclei of U2-OS cells were stained by the anti-RB
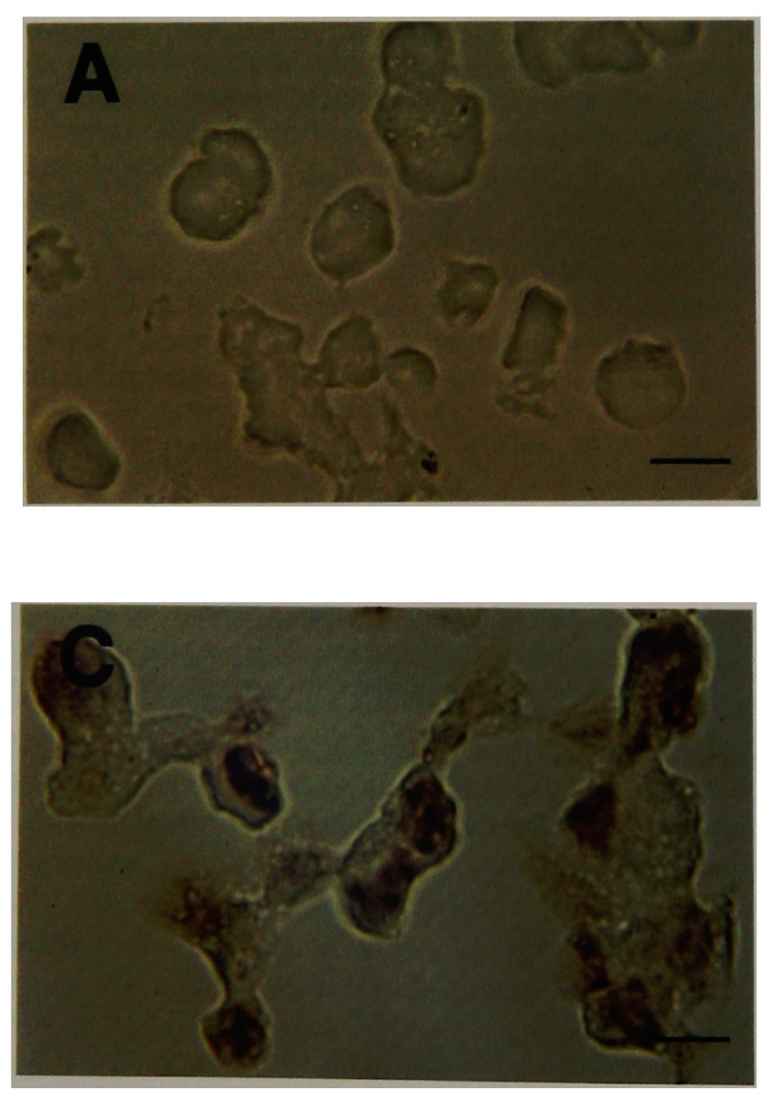

antibody, whereas none of the Saos-2 cells were stained (Fig. 2-A, B). Immunohistochemical studies showed no staining for RB in U2-OS cells of group 1 or in Saos-2 cells of all three groups (Fig. 3-A, D). Overall, 33\% of the

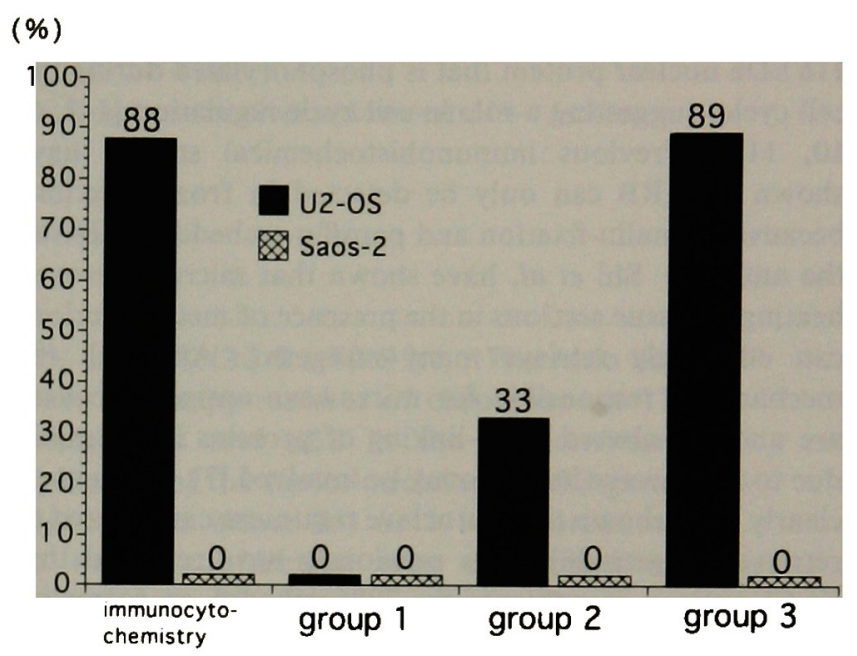

Fig. 4. Percentage of RB positive cells according to pretreatment method.
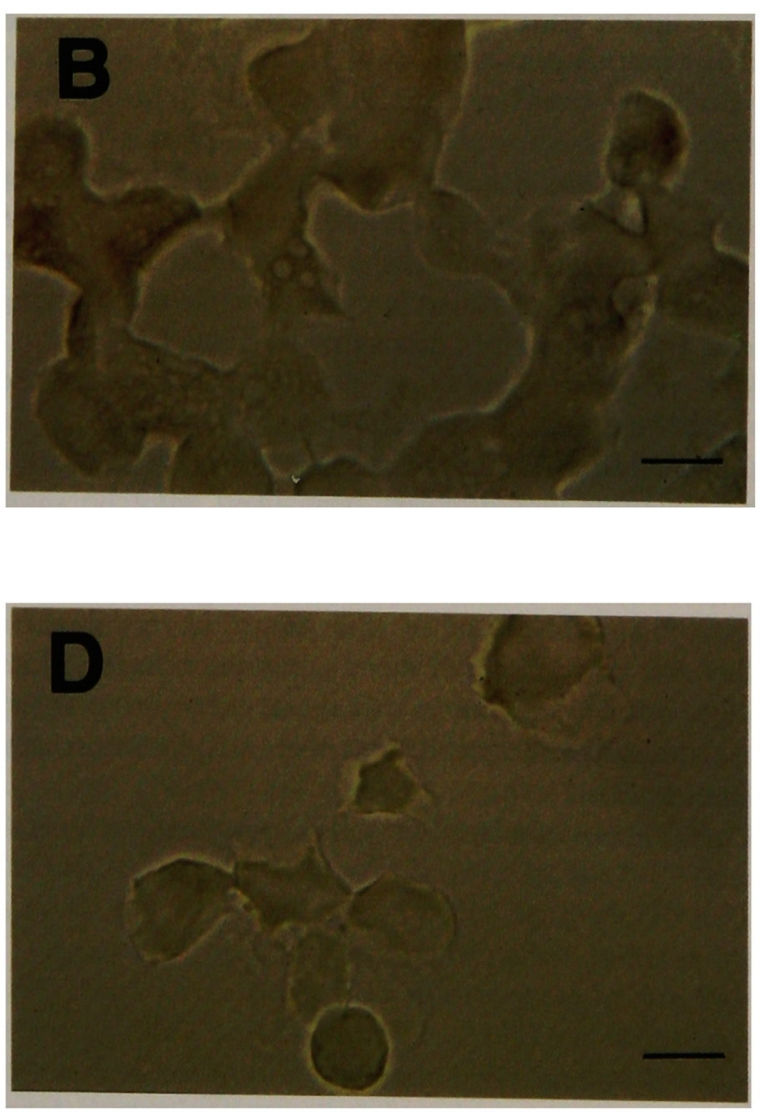

Fig. 3. Immunohistochemical staining of the RB in U2-OS (A, B, C) and Saos-2 cells (D). Specimens were fixed with $10 \%$ buffered formalin in PBS and embedded in paraffin. A: Sections stained by a conventional ABC method. NeitherU2-OS cells nor Saos- 2 cells were stained by the anti-RB antibody $(\times 100)$. B: Sections treated with microwave heating $(\times 100)$. C, D: Sections treated with autoclave heating $(\times 100)$.
$\mathrm{Bar}=20 \mu \mathrm{m}$. 
U2-OS cells in group 2 were stained weakly (Fig. 3B) and $89 \%$ of the U2-OS cells in group 3 were clearly stained by the anti-RB antibody (Fig. 3C).

\section{Discussion}

The retinoblastoma susceptibility gene encodes a 110$116 \mathrm{kDa}$ nuclear protein that is phosphorylated during the cell cycle, suggesting a role in cell cycle regulation $[1-3,5$, 10, 11]. Previous immunohistochemical studies have shown that RB can only be detected in frozen sections because formalin-fixation and paraffin-embedding destroy the antigen. Shi et al. have shown that microwave-oven heating of tissue sections in the presence of metal solutions can effectively retrieve many antigens. Although the mechanisms responsible for microwave antigen recovery are unclear, altered cross-linking of proteins by formalin due to microwave heating may be involved [7]. Shin et al. clearly have shown that autoclave treatment can be used to retrieve antigens [8]. We previously have reported that $\mathrm{Ki}-67$ antigen is retrieved in $70 \%$ ethanol or formalinfixed, paraffin-embedded sections of bone tumors using autoclave treatment, and that heat itself may be most important because higher temperature pretreatment produces stronger $\mathrm{Ki}-67$ immunoreactivity [9]. In the present study, we were able to demonstrate that the RB antigen can be effectively retrieved by microwave-oven heating or autoclave treatment.

Microwave ovens are often used to fix tissue. Shi et al. clearly have shown that several antigens can be retrieved from formalin-fixed, paraffin-embedded sections that are immersed in metal salt and heated in a microwave oven [7]. However, when compared to microwave-oven heating, autoclave treatment is more effective in retrieving antigens, but is also more damaging to tissue [9].

Our results suggest that the RB antigen can be retrieved by autoclave treatment (Fig. 3). Although the mechanisms responsible for microwave-oven or autoclave antigen recovery are unclear, heat itself may be most important because higher temperatures produced stronger intensity of RB immunostaining (Figs. 1, 4). The autoclave treatment described in this report is reproducible and has the advantage of producing little background staining. It also results in enhanced laboratory safety because the immersion solution does not contain metal salts such as lead.

These results confirm that autoclaving can be used to retrieve masked antigens, allowing the study of tissue previously considered unsuitable for immunohistochemical analysis. This technique also reduces the incidence of false-negative staining, and therefore, enhances diagnostic accuracy.

\section{References}

1. Benedict, W. F., Xu, H-J., Hu, S-X. and Takahashi, R.: Role of the retinoblastoma gene in the initiation and progression of human cancer. J. Clin. Invest. 85; 988-993, 1990.

2. Cance, W. G., Brennan, M. F., Dudas, M. E., Huang, C-M. and Cordon-Cordo, C.: Altered expression of the retinoblastoma gene product in human sarcomas. N. Engl. J. Med. 323; 1457-1462, 1990.

3. DeCaprio, J. A., Ludlow, J. W., Lynch, D., Furukawa, Y., Griffin, J., Worms, H. P., Huang, C-M. and Livingston, D. M.: The production of the retinoblastoma susceptibility gene has properties of a cell cycle regulatory element. Cell 58; 1085$1095,1989$.

4. Figge, J., Bakst, G., Weisheit, D., Solis, O. and Ross, J. S.: Image analysis quantitation of immunoreactive retinoblastoma protein in human thyroid neoplasms with a streptavidin-biotinperoxidase staining technique. Am. J. Pathol. 139; 1213-1219, 1991.

5. Lee, W. H., Shew, J. Y., Hong, F. D., Sery, T. W., Donoso, L. A., Young, L-J., Bookstein, R. and Lee, E. Y-H. P.: The retinoblastoma susceptibility gene encodes a nuclear phosphoprotein associated with DNA binding activity. Nature 329; 642-645, 1987.

6. Huang, H. -J.S., Yee, J. -K., Chen, P-H., Bookstein, R., Friedmann, T., Lee, E. Y. -H. P. and Lee, W. -H.: Suppression of the neoplastic phenotype by replacement of the RB gene in human cancer cells. Science 242; 1563-1565, 1988.

7. Shi, S. -R., Key, M. E. and Kalra, K. L.: Antigen retrieval in formalin-fixed, paraffin-embedded tissues. J. Histochem. Cytochem. 39; 741-748, 1991.

8. Shin, R. W., Iwaki, T., Kitamoto, T. and Tateishi, J.: Hydrated autoclave pretreatment enhances TAU immunoreactivity in formalin-fixed normal and Alzheimer's disease brain tissues. Lab. Invest. 64; 693-702, 1991.

9. Tsuji, Y., Kusuzaki, K., Hirasawa, Y., Serra, M. and Baldini, N.: Ki-67 antigen retrieval in formalin- or ethanol-fixed, paraffin-embedded tissue: An enhancement method for immunohistochemical staining with autoclave treatment. Acta Histochem. Cytochem. 30; 251-255, 1997.

10. Whyte, P., Buchkovich, K., Horowitzw, J. M., Friend, S. H., Raybuck, M., Weinberg, R. A. and Harlow, H.: Association between an oncogene and an anti-oncogene: the adenovirus E1A proteins bind to the retinoblastoma gene product. Nature 334; 124-129, 1988.

11. Xu, H-J., Hu, S-X. and Benedict, W. F.: Lack of nuclear RB protein staining in $G_{0}$ /middle $G_{1}$ cells: correlation to changes in total RB protein level. Oncogene 6; 1139-1146, 1991. 